\title{
SUSTENTABILIDAD DEL CRECIMIENTO SUBURBANO Construcción De Un Índice De Habitabilidad Para El Espacio Público
}

\author{
Ana María Compagnoni \\ Facultad de Arquitectura, Diseño y Urbanismo. Universidad de Buenos Aires \\ Director de Tesis: Silvia de Schiller \\ anacompa03@yahoo.com.ar
}

\begin{abstract}
RESUMEN
Este trabajo presenta los avances del proyecto de tesis doctoral cuyo principal problema a resolver es la habitabilidad en los espacios públicos del Área Metropolitana de Buenos Aires, caracterizada por un crecimiento suburbano fragmentado y disperso, con densificaciones focalizadas que afectan la calidad de estos espacios. En la búsqueda del equilibrio entre la compacidad y la dispersión, el objetivo es proporcionar herramientas para evaluar y guiar la interacción entre las variables del entorno urbano y la habitabilidad del espacio público. La hipótesis plantea la necesidad de integrar variables de forma, materialidad y funcionalidad en un índice que guíe el crecimiento equilibrado de la ciudad en relación con condiciones ambientales específicas. La metodología identifica, evalúa y compara espacios públicos en diferentes tipologías de crecimiento urbano, probando el índice desarrollado. Permite la observación y calificación de la habitabilidad en ciudades existentes y en condiciones de crecimiento potencial, contribuyendo con las futuras regulaciones de planificación.
\end{abstract}

Palabras clave: Índice de Habitabilidad, Espacio Público, Crecimiento Urbano Sustentable

\begin{abstract}
This paper presents the advances of PhD Thesis Project, whose main problem to solve is the habitability in the Buenos Aires Metropolitan Area public spaces, characterized by a fragmented and dispersed suburban growth with focused densifications that affect the quality of these spaces. In the search for a balance between Compactness and Dispersion, the aim is to provide tools to assess and guide the interaction between the urban environment variables and the public space habitability. The hypothesis raises the need to integrate variables of Form, Materiality and Functionality in an index that guides the balanced growth of the city in relation to specific environmental conditions. The methodology identifies, evaluates and compares Public Spaces in different urban growth typologies, testing the developed index. It allows the observation and qualification of habitability in existing cities and potential growth conditions, contributing to future planning regulations.
\end{abstract}

Key words: Habitability Index, Public Space, Sustainable Urban Growth 


\section{INTRODUCCIÓN}

Esta presentación constituye una síntesis del contenido de la tesis doctoral en curso y tiene por objetivo, dar un panorama general de la fundamentación, estructura y metodología de la misma así como comunicar los avances hechos en el desarrollo del proceso indagatorio.

Para la elección del tema-problema de este trabajo, fueron fundamentales los antecedentes de la autora en temas relativos a la sustentabilidad del hábitat construido, así como la experiencia realizada en el ámbito de la Dirección General de Planeamiento del GCABA ${ }^{1}$ durante los años 2008 y 2009, la cual estuvo orientada a la introducción de criterios bioclimáticos a proyectos de planeamiento urbano. Asimismo, el conocimiento directo de la problemática urbano - ambiental del RMBA ${ }^{2}$ y de las deficiencias en la calidad del espacio público urbano en este contexto, focalizó el interés del trabajo en la mejora de estas condiciones a partir de la consideración de los aspectos físicos y climáticos del entorno específico.

En primera instancia, se recopilaron referentes que dan un marco teórico a la conceptualización del espacio público urbano que constituye el objeto de estudio del trabajo. En este sentido, se buscó alimentar dicha conceptualización desde diferentes miradas sobre el espacio público, que dieran cuenta de las dimensiones diversas con que puede ser abordado el problema. Así surgieron definiciones de tipo formales, funcionales, perceptivas, sensoriales, etc. que a su vez reflejan la necesidad de considerar estos aspectos desde una mirada integral para evaluar la calidad de estos espacios a fin de asegurar el "habitar urbano" como condición indispensable para la manifestación de la vida ciudadana.

Con el objetivo de profundizar en el conocimiento de las condiciones de habitabilidad del espacio público urbano y desarrollar herramientas que permitan orientar el accionar de las administraciones públicas y de los proyectistas hacia el desarrollo de ciudades más integradas, se consideró fundamental el estudio de los procesos de crecimiento, así como la normativa que promovió dichos cambios en el uso del suelo, y los fenómenos mixtos de expansión y densificación que caracterizan al área de estudio. Estos fenómenos plantean el cuestionamiento de cuál es el nivel de compacidad aceptable en el contexto metropolitano de Buenos Aires, siendo el estudio de las condiciones de habitabilidad del Espacio Público Urbano un conocimiento clave para la determinación de los niveles de densificación aceptables para el crecimiento de la ciudad, adecuado a las condiciones ambientales de la RMBA.

Para este trabajo se toma un área de estudio diversa en su fisonomía urbana, caracterizada por la condición de "preexistencia" del medio antropizado que sirve de entorno experimental, permitiendo evaluar condiciones actuales del espacio público en diversas configuraciones o tipologías urbanas, y proponer cambios orientados a mejorar la performance de las unidades de análisis seleccionadas. La aplicación de un Índice que integre aspectos diversos de la habitabilidad urbana, permite además verificar la incidencia de las variables de diseño urbano en las condiciones de habitabilidad y ajustarlas en relación al medio.

\section{ORGANIZACION DE LA TESIS}

Esta tesis se estructura en tres partes dentro de las cuales se desarrollarán diferentes capítulos que a su vez incluyen temas específicos diferenciados en secciones. La primera parte condensa los Elementos Introductorios y el Estado del Arte, dentro del cual se desarrolla el Marco teórico - conceptual, el Estado actual del conocimiento y los Avances personales en la temática. La segunda parte abarca los Aspectos Metodológicos que incluyen: Reconocimiento y selección del área de estudio; Diagnóstico ambiental del área, Identificación y clasificación de las unidades de análisis, Desempeño ambiental de las unidades de análisis y Desarrollo y Aplicación del Índice de Habitabilidad del EPU ${ }^{3}$. La tercera parte constituye la Etapa Conclusiva del trabajo que, partiendo de la evaluación de resultados obtenidos en la sección anterior, desarrolla reflexiones sobre: la metodología aplicada para la construcción del Indice de Habitabilidad, el aporte a la normativa local y la Transferencia y aplicación en los procesos de Proyecto Urbano. Cada capítulo a su vez presenta conclusiones parciales que van construyendo nuevos y específicos saberes sobre cada tema desarrollado. La estructura general de la tesis se sintetiza en un Índice General que se planteó como "hipótesis de trabajo" (ECO 2004, pp121) ${ }^{4}$ para el Proyecto de Tesis. Esta presentación incluye el contenido del primer capítulo y una síntesis de los avances correspondientes a los capítulos subsiguientes.

\footnotetext{
${ }^{1}$ Gobierno de la Ciudad Autónoma de Buenos Aires

${ }^{2}$ Región Metropolitana de Buenos Aires

${ }^{3}$ Espacios Públicos Urbanos

4 Véase "Como se hace una Tesis", Cap IV, donde Humberto Eco propone escribir el Indice como Hipótesis de Trabajo para definir cuanto antes el ámbito de la tesis.
} 


\section{FUNDAMENTACIÓN DEL TEMA}

\subsection{Marco Teórico de Referencia}

Frente a los problemas de fragmentación urbana ocasionados por las formas de crecimiento urbano, promovidas durante las últimas décadas y enmarcado en los debates sobre la dimensión regional del concepto de Ciudades Compactas en países en desarrollo, el estudio y profundización sobre el rol del espacio público como motor de integración en entornos metropolitanos, resulta de especial interés para este trabajo. En relación al concepto de fragmentación urbana, Daniel Kozak en su tesis doctoral, refiere que "...la recurrencia de un término bajo diferentes interpretaciones...indica la emergencia de una problemática que requiere estudios urgentes". Por tal motivo se toma la fragmentación como parte del problema a resolver, a partir de acciones puntuales e integradas sobre el espacio público y considerando la forma urbana y las variables de diseño que intervienen en ella, como causal de la situación problemática. En relación a lo antedicho, Kozak (2008) interpreta el concepto de fragmentación referida al contexto del área metropolitana de Buenos Aires como "....una organización del espacio, entendido tanto como proceso como situación espacial resultante, en que límites impermeables y encapsulados adquieren un rol central. Es un estado de desarticulación y separación, frecuentemente asociado con divisiones socio- económicas y / o étnicas. La ciudad fragmentada es aquella en la cual la capacidad para usar y atravesar el espacio es dominada por el principio de exclusividad y donde se reduce el número de lugares de encuentro".

En 1992 la Cumbre de Rio plantea un cambio de rumbo en el paradigma de desarrollo, comprometiendo a los municipios a generar agendas locales, por considerar la escala local donde el reto de la ciudad sustentable se vislumbraba más accesible. "La sostenibilidad en las ciudades pasa necesariamente por la escala local, de ahí la importancia que adquiere la introducción de los criterios ambientales en los documentos de planeamiento." (Higueras, 2007). Sin embargo, aún hay municipios de áreas metropolitanas de Argentina que no han desarrollado los marcos normativos necesarios para la planificación del crecimiento sustentable de las ciudades. En este contexto, de Schiller (2002) afirmaba que "...La sustentabilidad urbana se ve fuertemente afectada por el rápido proceso de cambio que se produce en las características morfológicas del tejido, especialmente por el grado de "compactación" o "porosidad" del mismo, influyendo en la calidad ambiental de los espacios urbanos y micro urbanos". Murillo (2001) destaca a su vez, el fenómeno complejo que suma la "densificación", promovida por aumento de los costos de la tierra en algunos sectores, a la "dispersión" en suelos de bajo costo, generando impactos negativos al ambiente ya sea por sobrecarga o deficiencia de infraestructura; espacios verdes; calidad de aire etc. Por ello se deduce que, tanto los códigos de edificación como los urbanísticos han sido promotores de las diferentes tipologías edificatorias que definen la morfología del tejido urbano, resultando un verdadero testimonio de la evolución histórica de la ciudad y fuente de conocimiento sobre procesos de transformación y evolución del espacio público urbano.

La proliferación de espacios de uso común de dominio privado, a los que Kozak refiere como "impermeables y encapsulados" y que Gorelik (1995) califica como no lugares por su condición de puro interior, produce un fenómeno paralelo de pérdida del espacio exterior urbano. Esta tendencia, según de Schiller, plantea contradicciones en climas templados, donde "...se reemplazan las condiciones climáticas favorables por la necesidad de acondicionamiento artificial para lograr habitabilidad en espacios de uso común", por tanto "... recuperar el espacio urbano como componente vital de la ciudad permitirá mejorar las condiciones de vida y calidad ambiental al reducir la Isla Urbana de Calor con uso racional de los recursos" (de Schiller, 2005). En referencia a los impactos del hábitat construido en la Isla Urbana de Calor, Tumini (2012) en su tesis doctoral plantea que "El comportamiento del espacio urbano a nivel de micro-escala, no se ve influido solo por la cantidad de vegetación, de volumen edificado etc. sino que también por su organización espacial" resaltando el comportamiento diferencial en cuanto a la acumulación de calor en los cañones urbanos, en diferentes casos de estudio, en relación a los fenómenos micro-climáticos en altura. Para mitigar los efectos de la Isla Urbana de Calor, algunos autores proponen como medidas de mitigación: el control de densidad, especialmente FOS, uso de colores claros en techos y pavimentos, conservación y ampliación de áreas verdes y agua, ciudades compactas con transporte público, diseño del perfil de calles y espacios entre edificios, eficiencia energética en instalaciones, edificios y usos (de Schiller, S., Evans, J.M. y Katzschner, L., 2001).

Desde los países desarrollados, algunas vertientes rescatan y promueven la ciudad compacta como modelo para un territorio sustentable "donde la ciudad sea más ciudad y el campo más campo". (Rueda, 1999) Sin embargo, la definición de cuanta compacidad es admisible, dependerá de la consideración y evaluación de cómo interactúan los aspectos del hábitat construido con las condiciones particulares de cada entorno específico. En este sentido, Higueras aclara que "La forma urbana es el resultado de una compleja interacción 
de factores climáticos, económicos, sociales, políticos estratégicos, estéticos, técnicos y normativos y que muchas decisiones de planeamiento tienen influencia negativa con larga persistencia en el tiempo tanto a escala local como global..." (Higueras E. 2007) Por lo que la regulación del tejido urbano con criterios sustentables se hace inminente, para asegurar mejores condiciones de habitabilidad urbana.

Salvador Rueda relaciona también la idea de ciudad ligada a la existencia de un espacio público de calidad y destaca el valor de la diversidad, asignándole un rol fundamental al considerar que el espacio público "...marca los límites de ciudad, donde no lo hay puede hablarse de urbanización, pero difícilmente de ciudad". (Rueda 1999). También Borja (1999) plantea al espacio público como desafío y oportunidad para la justicia urbana y la noción de "hacer ciudad sobre la ciudad", entendiendo como tal la articulación de centralidades integradoras, polivalentes, constituidas por tejidos urbanos heterogéneos, social y funcionalmente, contribuyendo así con la idea de diversidad. Estas ideas, refuerzan el rol articulador que puede adoptar el espacio público tanto en sentido funcional como ambiental y la contribución del mismo a un proceso de "defragmentación urbana" que restituya las condiciones de habitabilidad del espacio público, permitiendo el desarrollo y las manifestaciones de los sujetos.

Respecto del concepto de Habitabilidad Urbana, diversos autores abordan el tema desde diferentes perspectivas en consonancia con su formación y experiencia profesional aportando a esta tesis aspectos complementarios que son tenidos en cuenta para la definición de un concepto de habitabilidad compatible con las condiciones locales. Así también, es necesario reflexionar sobre el concepto de Espacio Público para luego definir su condición de "habitable". En este sentido, Odilia Suárez (1995) define al Espacio Público como "...vacío con-formado por las edificaciones y elementos que lo rodean." Y aclara que "...cuando ese vacío se transforma en ámbito, pasa de ser fondo a ser figura". Arrese (1995) completa esa idea con el concepto de "par opuesto" o "contra-forma estricta del espacio privado", destacando las capacidades compartidas e interrelacionadas entre ambos, que dan origen a las diferentes escalas de la relación comunidad-privacidad que cada cultura manifiesta a través de ellos. Marengo de Tapia (1995) destaca los roles social; ecológico; paisajístico; de protección ambiental y amenidad visual que debe caracterizar a este tipo de espacios. En cuanto a la calidad de los espacios abiertos urbanos, aclara que son espacios "...para el uso del hombre...para el ocio... para el tiempo libre y cuyo objetivo principal es la búsqueda del bienestar." diferenciando además dos valores que cualifican el espacio abierto urbano: ambientales y paisajísticos. Iglesia (2010) menciona que habitar supone hacer habitable un espacio, y destaca la idea de espacio vivido donde está implícita la noción de entorno, este concepto acentúa la relación del hombre con su hábitat, considerándola como flujo de experiencias implicadas unas con otras en el tiempo y en el espacio. Resalta que "...el espacio para habitar no puede ser el lugar de nada o el lugar de nadie." Concordante con estas ideas, Schiller (2002) argumenta que "...la sustentabilidad del ambiente construido depende... del confort y nivel de atracción y percepción de estos espacios por parte de los usuarios, así como de su aptitud para ser habitados." La autora ratifica lo que Chermayeff y Alexander (1963) reflexionaban sobre el fracaso suburbano y la tierra de nadie urbana, al mencionar la importancia que adquiere el diseño y el manejo de las escalas en los espacios exteriores ....". Asimismo, Jan Gehl remarca que "...la dispersión de acontecimientos y personas es un fenómeno habitual en casi todas las zonas suburbanas del mundo entero..." contrastándolo con aquellas "...estructuras urbanas que agrupan con coherencias acontecimientos y personas en un trazado claro en que los espacios públicos son los elementos más importantes en la planta de la ciudad..." Complementariamente, "...la integración de varias actividades y funciones en los espacios públicos y a su alrededor permite que las personas implicadas actúen juntas y que se estimulen unas a otras..." (Gehl, 2013). Esto promueve la integración y complejidad propias de la escala barrial, que es necesario recuperar para contribuir a la habitabilidad de esos espacios y evidencia la relación entre el diseño formal, material y funcional de los Espacios Públicos.

"El sistema del espacio público tiene vinculadas variables ambientales definidas como atributos o cualidades de los componentes interrelacionados del sistema, cuyo comportamiento puede ser evaluado a través de su medición para un período de tiempo definido por medio de indicadores y así facilitar su intervención estratégica, al contribuir con cambios significativos sobre los impactos ambientales producidos. (Pinzón Botero y Echeverri Álvarez, 2010). Estas aseveraciones ponen de manifiesto la posibilidad de construir un Indice que reúna aquellos indicadores claves que sinteticen esos atributos relativos a la habitabilidad del sistema espacio público para evaluar y orientar el comportamiento o desempeño del mismo, en este sentido. 


\subsection{Antecedentes en el Tema}

La AEUB ${ }^{5}$ establece una serie de indicadores para el Espacio Público y la Movilidad y aplica una Metodología a diferentes ciudades como Lugo y Vitoria- Gasteiz. En ella se describen "...las variables que condicionan la percepción de un determinado espacio en función a la respuesta por parte de un individuo..." las cuales se clasifican en cuatro grupos relacionadas con: morfología y compacidad, elementos de atracción, condiciones de confort y accesibilidad simultánea a servicios. Los tres primeros determinan el grado de habitabilidad en el espacio público, el cuarto determina la habitabilidad en el entornono urbano. La habitabilidad urbana, por tanto, será producto de la suma de ambos índices." Se establecen rangos de valoración y se toman las calles como unidades de análisis, las cuales son diferenciadas por: Orientación, Relación entre ancho y altura de la edificación y Tipología del Cañón. Luego se analiza la Habitabilidad Urbana en relación al escenario actual y se plantean diversos escenarios futuros para la aplicación de dicho análisis. Roy Allan Jimenez (2016 a) adhiere a esta clasificación y asevera que "La habitabilidad urbana es un indicador que mide las condiciones del entorno que permiten una buena calidad de vida para los habitantes de una ciudad" y aclara que "El índice de habitabilidad es una manera de relacionar los parámetros morfológicos de la ciudad con los estímulos y realidades de vida que ofrece. Es una manera novedosa de transformar las "restricciones urbanísticas" en condiciones para potenciar el ambiente urbano. Este indicador mide las características del entorno que permiten una buena calidad de vida para los habitantes de una ciudad." (Jimenez, 2016 b).

Asimismo, la AEUB desarrolla un documento para la Certificación del Urbanismo Ecológico, donde analiza los diferentes métodos de certificación aplicables a desarrollos urbanos. En ese documento se destaca que para los valores de referencia de los indicadores cuantitativos se establecen "protocolos de mínimos y máximos", aclarando que estos valores han sido establecidos en base al contexto y modelo urbano ordinario del lugar donde ha sido desarrollado la certificación los cuales pueden no ser aplicables en contextos o realidades diferentes. Esta aclaración es fundamental en cuanto a la necesidad de adaptación de indicadores que pretendan medir aspectos de habitabilidad urbana, ya que estos están íntimamente relacionados con factores físicos y ambientales del entorno. Esta Guía Metodológica constituye un antecedente hacia la adaptación local de métodos de evaluación de sostenibilidad, tanto de las de transformación del medio urbano consolidado como de nuevos desarrollos urbanísticos.

En cuanto a la idea de construir un Indice de Habitabilidad, "Algunos sistemas de indicadores no se satisfacen con seleccionar una o más variables descriptivas de un fenómeno como mecanismo de síntesis de la información necesaria para tomar decisiones, sino que fusionan la información contenida en varias de ellas en una sola expresión numérica. La magnitud resultante de tal fusión se denomina índice, y es una magnitud adimensional pues resulta de la adición ponderada, según el procedimiento que se elija, de diversas unidades de medida.... El beneficio obtenido se traduce en una mayor síntesis de la información relevante y una mayor eficacia como input en la toma de decisiones. El sistema de indicadores urbanos es un conjunto ordenado de variables sintéticas cuyo objetivo es proveer de una visión totalizadora respecto a los intereses predominantes relativos a la realidad urbana de que se trate." (Rueda Palenzuela en Leva 2005)

En el contexto local, el Gobierno de la Ciudad Autónoma de Buenos Aires desarrolló el Modelo Territorial 2010-2060 (MDU-GCABA, 2011) orientado al logro de la Ciudad Sustentable, desarrollando el Indice de Sustentabilidad Urbana que establece una serie de indicadores para cada uno de los ejes prioritarios establecidos por el Plan Urbano Ambiental. El eje de Espacio Público incluye indicadores relacionados con aspectos ambientales, de compacidad y de espacios verdes los que fueron transferidos desde otros contextos con condiciones ambientales y climáticas diferentes a las de Buenos Aires, por lo que es fácil inferir que la aplicación de dicho indicador no daría los mismos resultados en términos de confort y satisfacción en el espacio público. Sin embargo, dentro del panel se reconocen algunos indicadores que podrían aportar información útil sobre la habitabilidad de los espacios públicos. Considerando que históricamente las normativas a escala municipal han tomado como referencia los documentos desarrollados en el ámbito de la ciudad de Buenos Aires, estos avances en el contexto local dan pie a suponer que la profundización en la búsqueda de un mayor ajuste en procedimientos y herramientas de evaluación de las condiciones de habitabilidad urbana, serán un aporte al planeamiento y la gestión de las ciudades.

\section{DEFINICIÓN DEL PROBLEMA Y ENFOQUE DE LA TESIS}

En relación a la bibliografía consultada, se define como problema a resolver la contribución a mejorar las condiciones de habitabilidad del espacio público en entornos urbanos afectados por los procesos de

\footnotetext{
${ }^{5}$ Agencia de Ecología Urbana de Barcelona
} 
crecimiento, promotores de la fragmentación y dispersión urbana. Los interrogantes que surgen y a los cuales se intenta dar respuesta con el desarrollo de esta tesis son los siguientes:

a. ¿Cómo medir y prever el desempeño ambiental del Hábitat Construido y sus consecuencias en la escena urbana (tejido urbano y espacio público)

b. ¿Cuáles son las variables que permiten establecer relaciones entre el hábitat construido y los efectos ambientales sobre el espacio público urbano para la construcción de indicadores?

c. ¿Qué indicadores pueden integrarse en un Índice que permita establecer niveles de habitabilidad urbana en el contexto del RMBA?

En este sentido, la premisa de investigación propuesta para esta tesis se centra en la interrelación e incidencia recíproca entre variables de diseño del hábitat construido (aspectos de morfología, materialidad, funcionalidad, etc.) y aspectos del entorno físico, climático, etc. y cómo estos impactan en la percepción subjetiva y la habitabilidad de los EPU. El trabajo abordará aspectos de las dimensiones: proyectual, urbanística y ambiental para definir indicadores que permitan prever el desempeño de crecimientos urbanos futuros así como evaluar propuestas alternativas de crecimiento sustentable en la ciudad existente. Se trata de desarrollar un conocimiento de tipo prospectivo ya que tiende a orientar tanto los procesos proyectuales como la planificación sobre entornos urbanos futuros, así como el diagnóstico de condiciones urbanoambientales existentes, tendientes a proponer mejoras. Asimismo, se trata de un conocimiento metódico y sistemático en cuanto a sus procedimientos, que posibilite su aplicación a casos similares dentro del área metropolitana y su adaptación, según el contexto, a otras regiones metropolitanas del país.

\section{OBJETIVOS}

\subsection{Generales}

- Explicitar la interacción entre las variables de diseño del hábitat construido y la habitabiliad del espacio público urbano a través del uso de indicadores y la construcción de un índice específico.

- Contribuir a la orientación del accionar proyectual en la búsqueda de un mayor equilibrio entre el espacio construido y el espacio público de uso comunitario, contemplando la diversidad de factores incidentes y teniendo en cuenta las particularidades que definen la fisonomía del entorno.

- Aportar al desarrollo de normativas de planeamiento orientadas a promover formas de crecimiento urbano integradoras y mejorar la habitabilidad del espacio público, minimizando a su vez el impacto del hábitat construido sobre el ambiente.

\subsection{Específicos}

- Indagar sobre los antecedentes existentes en la evaluación del confort y satisfacción en espacios exteriores urbanos para establecer valores de referencia y validar métodos analíticos y herramientas de simulación.

- Identificar las variables del medio y del hábitat construido que permitan desarrollar indicadores para definir un Indice que integre las dimensiones: morfológica, material y funcional para la calificación de Habitabilidad de los Espacios Públicos Urbanos

- Desarrollar una metodología de fácil aplicación y replicable en otros contextos metropolitanos en crecimiento

\section{HIPÓTESIS GENERAL}

En base al marco teórico consultado, esta investigación se propone demostrar que: "La habitabilidad del Espacio Público Urbano depende de variables de Morfología, Materialidad y Funcionalidad que definen al propio espacio, la cual es posible evaluar y predecir aplicando un Índice Sintético que integre indicadores ajustados a las condiciones micro-climáticos específicas, sirviendo éste como herramienta orientativa para calificar el desempeño de espacios públicos abiertos y cuantificar la incidencia de variables de diseño en la calidad ambiental de los mismos". En este sentido, la validación de la hipótesis consiste en demostrar que son esas variables las que influyen y están asociadas a la habitabilidad de esos espacios. Por lo que el índice a construir será una síntesis de los componentes relevantes de la habitabilidad.

\section{FUNDAMENTACIÓN DEL AREA DE ESTUDIO}

En el marco de los lineamientos para el desarrollo de ciudades más sustentables promovido y reforzado por la Nueva Agenda Urbana Hábitat III (2016) y considerando que la disponibilidad de tierras dentro de las áreas urbanas es limitada, la indagación sobre las formas de densificación posibles en áreas metropolitanas resulta 
un nicho de atracción para desarrolladores y profesionales. Por tal motivo, el estudio y evaluación de los efectos que estas formas de crecimiento puedan ocasionar en la calidad y habitabilidad del espacio público suburbano, resulta de especial interés para el trabajo. La Región Metropolitana de Buenos Aires se caracteriza por un crecimiento no planificado con centralidades que se expandieron inicialmente desde las vías férreas y se consolidaron con las autopistas en las últimas décadas, producto del modelo de desarrollo imperante, generando un tejido con grandes zonas mono-funcionales y con densidades dispares sin correlato en su espacio público. En este proceso, se verifica la desarticulación que sufrió la metrópolis bonaerense como consecuencia de adoptar para los suburbios modelos ideales de ciudad que, sumado al fenómeno de densificación de guetos de pobreza, produjo el consecuente deterioro de la mixtura urbana original.

Teniendo en cuenta que el proceso de crecimiento de la RMBA está limitado en su extensión por territorios productivos, que es necesario conservar, la densificación es la alternativa más promovida desde los municipios para dar respuesta al desarrollo urbano. Dentro de la región, el Partido de Gral. San Martín presenta una fisonomía de evidente fragmentación urbana que se caracteriza por: zonificación de usos, existencia de grandes vacíos urbanos, degradación del espacio público y proliferación de grandes contenedores industriales y comerciales, que generan una evidente ruptura del tejido, producto de la sinergia entre los factores mencionados. A ello, se agrega la falta de conectividad del Partido con la ciudad y los municipios que lo rodean. Paralelamente, en los últimos años, se ha generado un proceso creciente de densificación que se ajusta a la normativa existente, desconociendo estándares de sustentabilidad urbana y favoreciendo la proliferación de edificios en altura en gran parte del tejido, sin una relación lógica con la disponibilidad de espacios públicos ni de infraestructura de servicios.

Por tales motivos, se considera al Área del Partido de Gral. San Martín como un recorte de la realidad, adecuado para la experimentación sobre el espacio público como amortiguador de esas fallas evidentes en la región. Se propone la identificación de situaciones típicas y replicables, para su aplicación en sectores urbanos de diferente escala y nivel de complejidad. En este sentido, para el reconocimiento de las distintas formas del crecimiento urbano, Solá Morales i Rubio analiza la evolución de las ciudades españolas llegando a clasificar nueve procesos tipológicos principales, incluyendo operaciones de transformación en la ciudad existente. Este marco teórico aporta una metodología de reconocimiento de las formas de crecimiento desde una visión proyectual, más que desde una visión geográfica del mismo. "Miradas de esta forma, las diferentes maneras de organizar calles, solares (lotes) y casas -infraestructuras, parcelas y tipos- son formas de Urbanización, Parcelación y Edificación que, en sus diferentes combinaciones, dan lugar a las formas urbanas. (Solá Morales i Rubió, 1997, p.15).

Teniendo además en cuenta el déficit que presenta el Partido en cuanto a espacios verdes públicos y la concentración de grandes vacíos en contraposición a zonas de tejido predominantemente industrial o degradadas sin arbolado público, las condiciones ambientales del Partido resultan muy dispares. Por lo que el desarrollo de normativa que regule la distribución del verde público con criterios de equidad, resulta de especial interés. En este sentido, resulta de interés identificar potenciales acciones de "acupuntura urbana" (Lerner, 2005) donde la calificación y aprovechamiento bioclimático de especies verdes favorecerían condiciones más confortables en el espacio público para un uso sostenido en el tiempo.

\section{RESEÑA METODOLÓGICA}

Este proyecto plantea una metodología basada en el estudio de casos en un recorte representativo de la RMBA para el análisis y evaluación de las condiciones de habitabilidad en los espacios públicos resultantes de las diferentes tipologías de crecimiento urbano, a fin de identificar aspectos del medio construido que interactúan con aspectos ambientales locales y condicionan la habitabilidad de los espacios públicos urbanos. La propuesta incluye trabajos de investigación bibliográfica y documental, relevamiento y mediciones en campo, trabajo de laboratorio y simulaciones computarizadas, que contribuyen a demostrar la hipótesis planteada en cuanto a la utilidad del uso de un Indice Sintético de Habitabilidad para el EPU, que integre indicadores de diversas dimensiones para orientar el crecimiento urbano sustentable del área metropolitana y asegurar condiciones aceptables para el desarrollo de las actividades en espacios abiertos urbanos. Se trata de un proceso analítico y empírico que contempla etapas propositivas sobre escenarios proyectuales de la escena urbana a los fines de definir las potencialidades del uso de ciertos indicadores en forma conjunta. La metodología planteada se compone de 6 etapas que no responden a una linealidad temporal, pudiendo haber actividades que se desarrollen de forma simultánea, para lo cual se presenta un esquema metodológico que sintetiza el desarrollo del trabajo. (Fig. 1) 


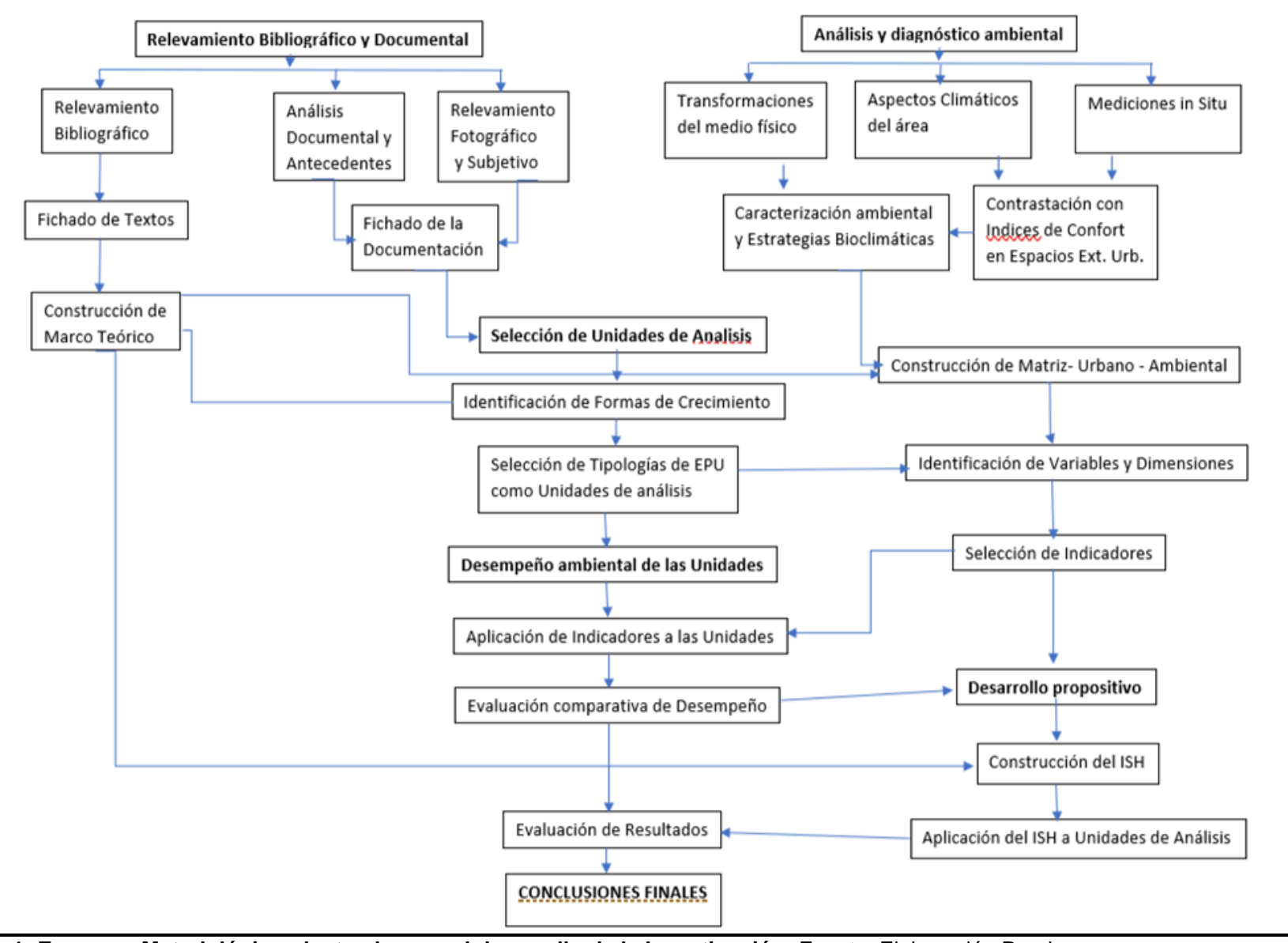

Fig.1: Esquema Metodológico planteado para el desarrollo de la Investigación- Fuente: Elaboración Propia

\section{ESTADO DE AVANCE DE LA TESIS}

\subsection{Reconocimiento del área de estudio}

Paralelamente al relevamiento bibliográfico que contribuye a la construcción del Marco Teórico, el relevamiento documental permite analizar las causas y consecuencias del crecimiento urbano, desde el contexto latinoamericano hasta el área específica de estudio. Se estudiaron las condiciones originales del paisaje local y el avance de la ciudad sobre el territorio metropolitano en sus procesos de extensión y densificación, así como los problemas de fragmentación y ruptura del tejido con repercusiones en las condiciones ambientales sobre el área del Partido de Gral. San Martin (Figs. 2 a 6). Se analizó también el crecimiento residencial formal e informal y sus consecuencias ambientales en el área de estudio (Figs.7 y 8).

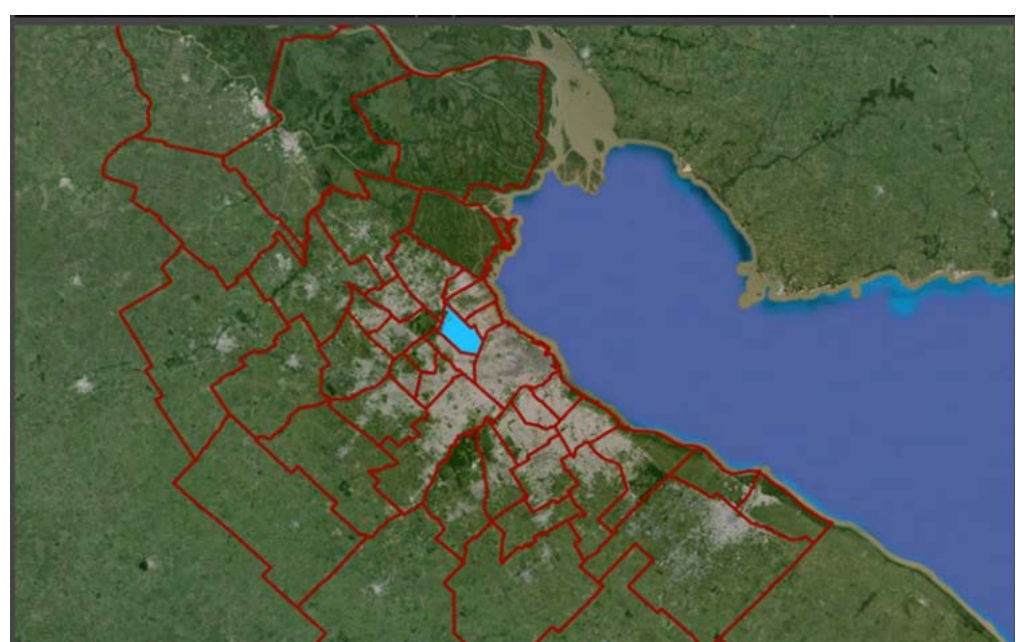

Fig 2: Localización del área de estudio dentro de la RMBA.

Fuente: Gentileza de la Dirección de Planeamiento del Partido de Gral San Martin 


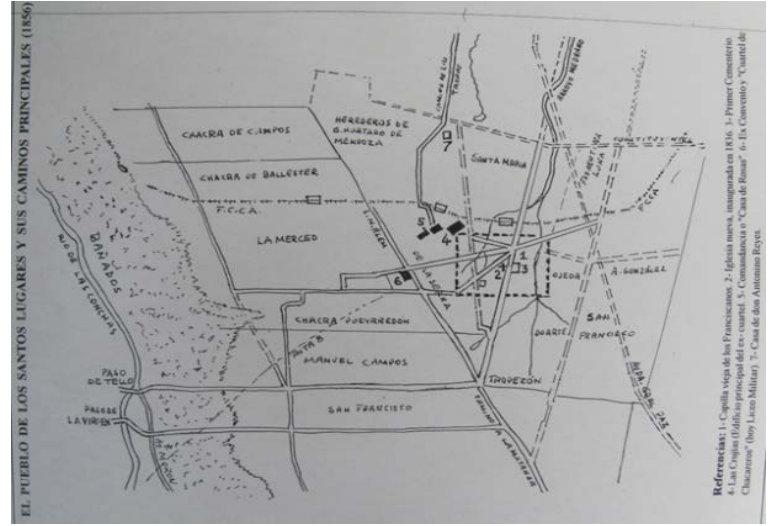

Fig.3: Esquema planimétrico de distribución de tierras y trazado de caminos en 1856 (en punteado el que luego sería el casco urbano) Fuente: Archivo histórico de Gral. San Martín

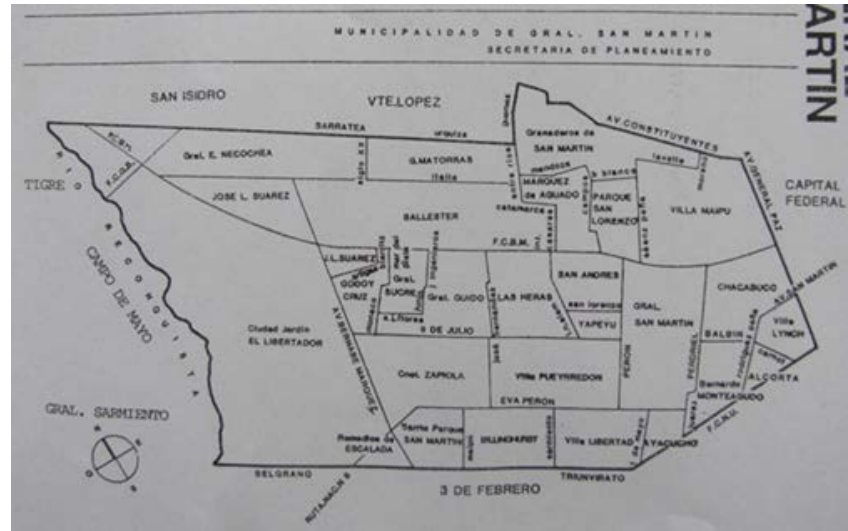

Fig.4: Delimitación y subdivisión definitiva del partido de Gral. San Martín en sus diferentes barrios que aún conservan sus nombres originales. Fuente: Archivo histórico de Gral. San Martín

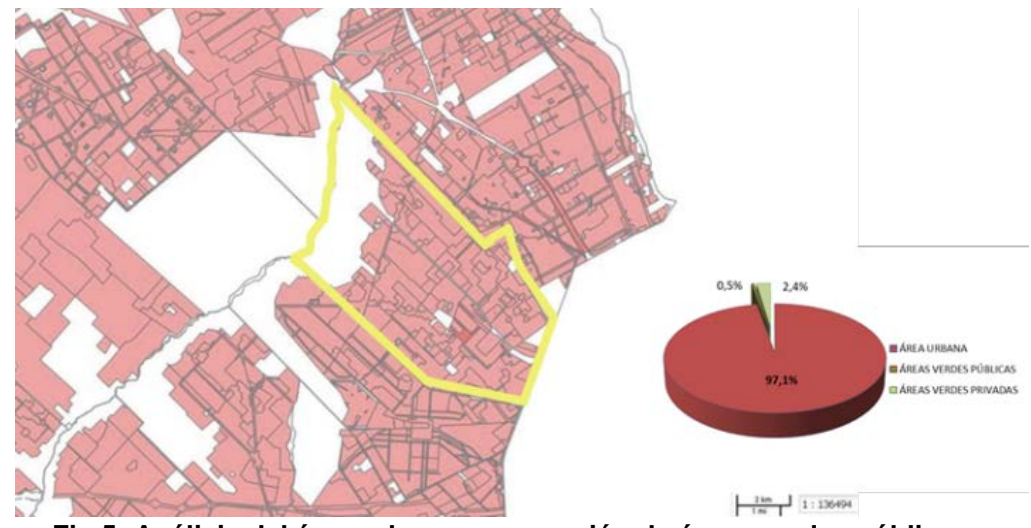

Fig.5: Análisis del área urbana y proporción de áreas verdes públicas y privadas en el Pdo. de Gral. S. Martin.

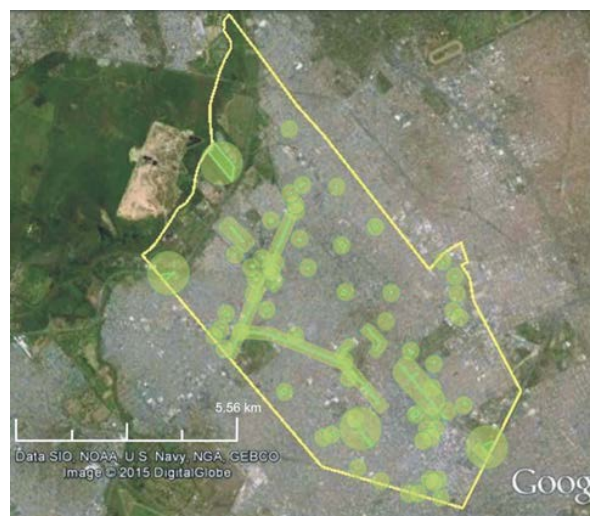

Fig. 6: Análisis de los espacios verdes públicos y su área de influencia

Fuente: Elaboración propia en base a imágenes desarrolladas en el marco del Proyecto UBACyT dirigido por la autora

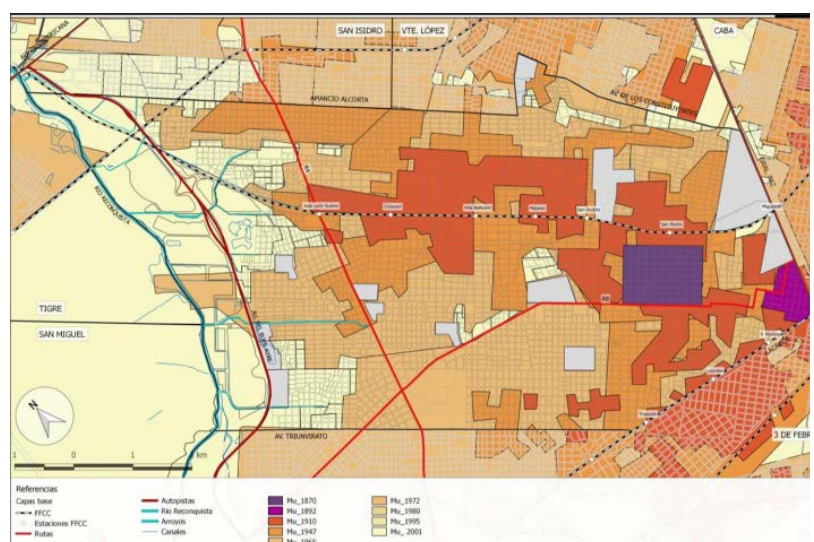

Fig. 7: Crecimiento de la mancha urbana en base al estudio de los Radios Censales. Fuente: Dirección de Planeamiento de Gral. San Martin.

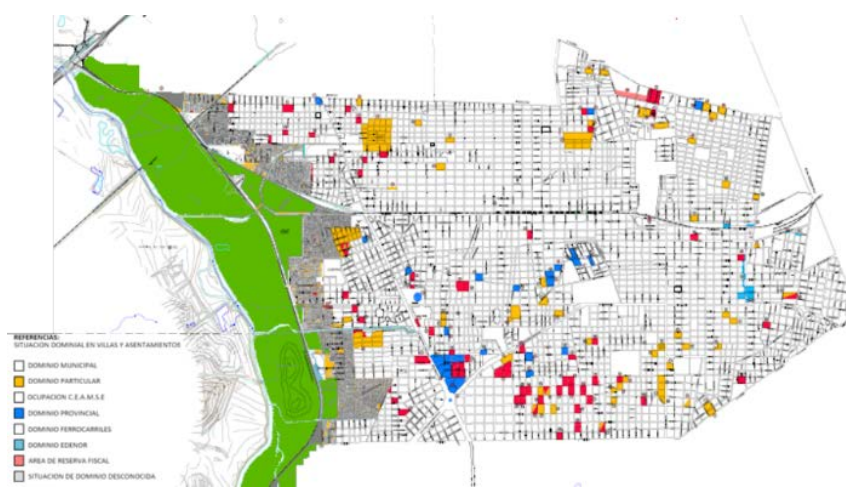

Fig. 8: Plano de Localización y Situación Dominial de los asentamientos informales. Fuente: Secretaría de Obras y Servicios Públicos de la Municipalidad de General San Martín.

Se analiza también la Ley Provincial 8912 sobre uso del suelo y el $\mathrm{COU}^{6}$ como marco normativo vigente y promotor del actual estado de crecimiento y consolidación del tejido. Así también, el PE ${ }^{7}$ y el PUA ${ }^{8}$ local como herramientas normativas con potencialidad de promover eco-proyectos urbanos y el rol potencial del EPU como integrador de la fragmentación existente. Estos temas fueron desarrollados en el marco de seminarios doctorales encontrándose en proceso de edición y elaboración de las conclusiones correspondientes y el material documental recopilado está siendo sistematizado para su compilación en anexos.

\footnotetext{
${ }^{6}$ Código de Ordenamiento Urbano

${ }^{7}$ Plan Estratégico

${ }^{8}$ Plan Urbano Ambiental
} 


\subsection{Diagnóstico ambiental del área}

Esta etapa parte del reconocimiento de las transformaciones del medio físico y natural (Fig.9), analizando las variables físicas y climáticas del entorno, que corresponden a la localización específica del área de estudio. Se definen las condiciones de confort en espacios exteriores para el microclima del partido de General San Martín para definir las estrategias bioclimáticas que debieran ser contempladas en la planificación urbana a fin de lograr condiciones de habitabilidad tanto en el interior del tejido como en los EPU. Este proceso termina con la Caracterización Ambiental y Estrategias Bioclimáticas que servirán para evaluar luego las formas de crecimiento urbano y las tipologías de EPU en relación a dichas condiciones óptimas de confort.

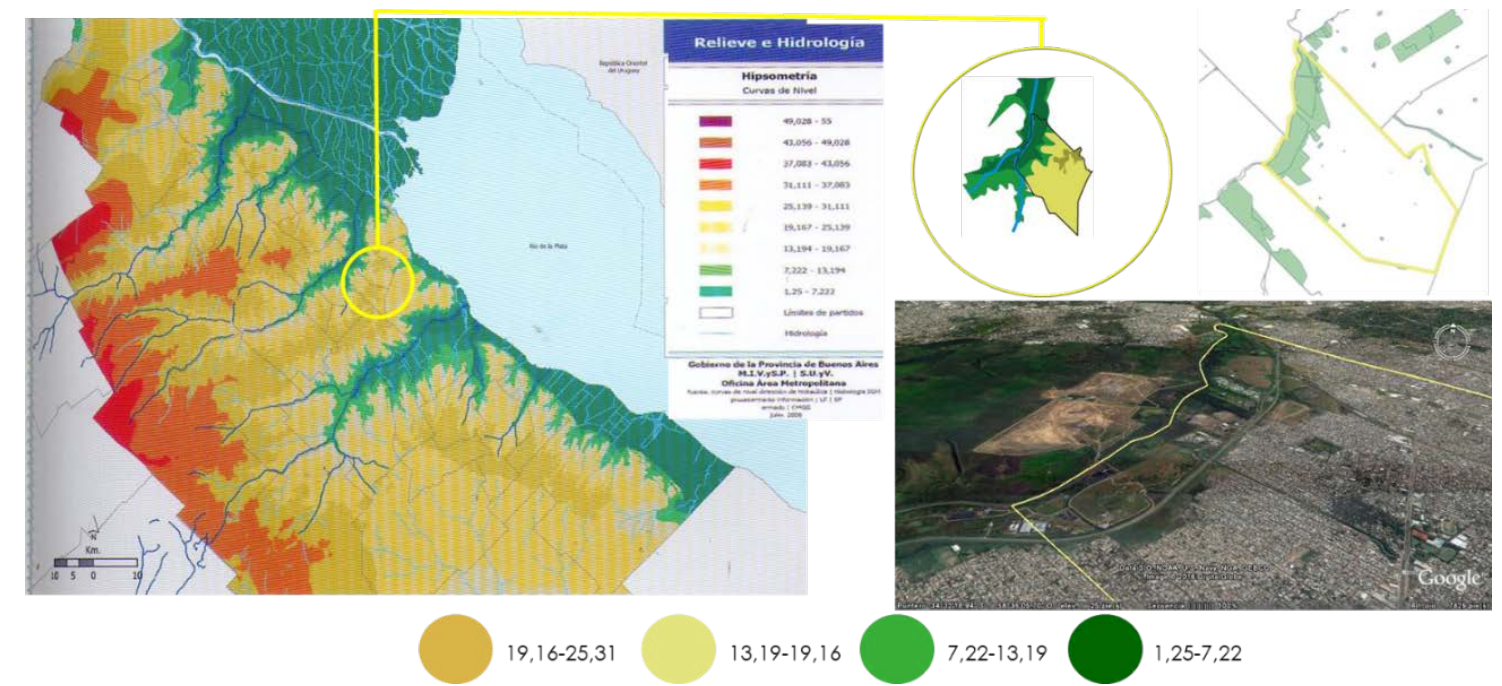

Fig. 9: Estudio de condiciones naturales del terreno en el área y su situación actual en la zona del Rio Reconquista. Fuente: Elaboración propia en base a imágenes desarrolladas en el marco del Proyecto UBACyT dirigido por la autora.

Esta etapa se encuentra razonablemente avanzada en cuanto a la caracterización de las condiciones ambientales del área de estudio y la identificación de las estrategias de confort para espacios exteriores en base al climograma de confort de Givoni y el método de Triángulos Verdes de Evans (Figs 10 y 11).
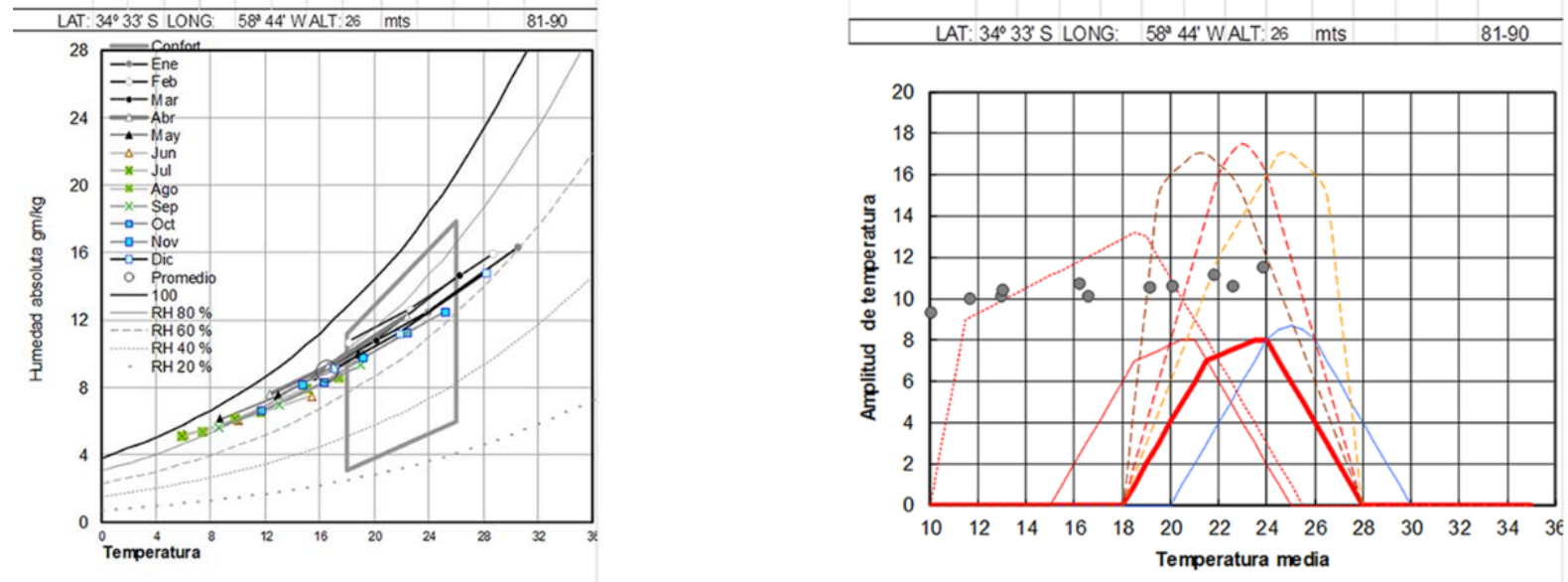

Fig.10: Gráficos de Confort para el área de estudio en base al Climograma de Givoni y Triángulos Verdes de Evans. Fuente: E-Clim - Planilla de Calculo desarrollada en el CIHE- FADU- UBA?

Complementariamente, la búsqueda de antecedentes sobre Indices de confort y satisfacción en espacios exteriores urbanos, actualmente en proceso, contribuirá a definir un Indice de referencia para evaluar condiciones de confort-disconfort en cada unidad de análisis a partir del mapeo de los registros tomados in situ y pudiendo relacionar estas condiciones con aspectos del hábitat construido observados en los puntos de medición y registrados en planillas confeccionadas a tal fin. Asimismo, el relevamiento subjetivo de confort servirá para contrastar los valores medidos con la percepción del usuario en dichas situaciones urbanas.

\footnotetext{
${ }^{9}$ Centro de Investigación, Hábitat y Energía - Facultad de Arquitectura, Diseño y Urbanismo- Universidad de Buenos Aires
} 


\begin{tabular}{|l|c|c|c|c|c|c|c|c|c|c|c|c|}
\hline \multirow{2}{*}{ VARIABLE } & \multicolumn{7}{|c|}{ MESES } \\
\hline & 1 & 2 & 3 & 4 & 5 & 6 & 7 & 8 & 9 & 10 & 11 & 12 \\
\hline Temperaturas confortables de dia & & & & & & & & & & & & \\
\hline Meses F rios durante el dia & & & & & & & & & & & & \\
\hline Meses Calurosos durante el dia & & & & & & & & & & & & \\
\hline Meses con exceso de Hum edad & & & & & & & & & & & & \\
\hline Meses secos & & & & & & & & & & & & \\
\hline Amplitud tem ica superior a 140 C & & & & & & & & & & & & \\
\hline Cielo Claro & & & & & & & & & & & & \\
\hline Cielo nublado & & & & & & & & & & & & \\
\hline Vientos leves & & & & & & & & & & & & \\
\hline Vientos de alta velocidad & & & & & & & & & & & & \\
\hline
\end{tabular}

\begin{tabular}{|l|l|l|l|l|l|l|l|l|l|l|l|l|}
\hline Situación de Confort o Dsiconfort & D & D & C & C & D & D & D & D & D & C & C & D \\
\hline
\end{tabular}

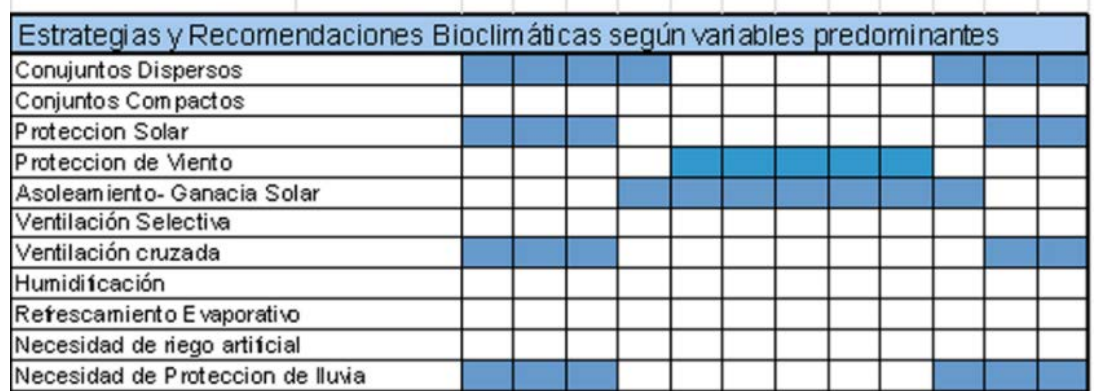

Fig. 11: Síntesis de Estrategias Bioclimáticas para el área de estudio

Fuente: Elaboración Propia en el marco del Proyecto UBACyT 2014-2017

\subsection{Identificación de casos de estudio y unidades de análisis}

Este capítulo comienza con la identificación de las tipologías de crecimiento o mosaicos urbanos que predominan en el área de estudio, para lo cual se realiza una síntesis de tipologías en base al aporte del marco teórico consultado de Solá Morales i Rubió, Rodriguez Tarduchi e Higueras, tomando aquellas tipologías reconocidas por el planeamiento y descartando aquellas que están fuera del crecimiento formal de la ciudad. La matriz de anclaje de la investigación será la escala de mosaico o tipología de crecimiento, con las variables propias de esa escala y del espacio público que la caracteriza, teniendo en cuenta que, si bien hay variables que corresponden a una escala supra o de nivel inferior, será necesario contemplarlas a los fines de este trabajo. Tal sería el caso de las condiciones materiales de la envolvente de los edificios que limitan directamente con los espacios públicos y constituyen la propia envolvente del mismo.

Las Figs. 12 y 13 dan muestra de la diversidad de tejido que generan las diferentes tipologías de crecimiento en el área de estudio. Asimismo, las Figs.14 y 15 dan cuenta de algunos aspectos relevantes de la morfología urbana que condicionan la calidad de los espacios públicos, como lo es la Permeabilidad del Tejido que interactúa con variables de clima y condiciona el confort. Así como las tipologías edilicias, sus alturas, uso del lote, etc. que condicionan dicha permeabilidad (Figs. 16 y 17 ).

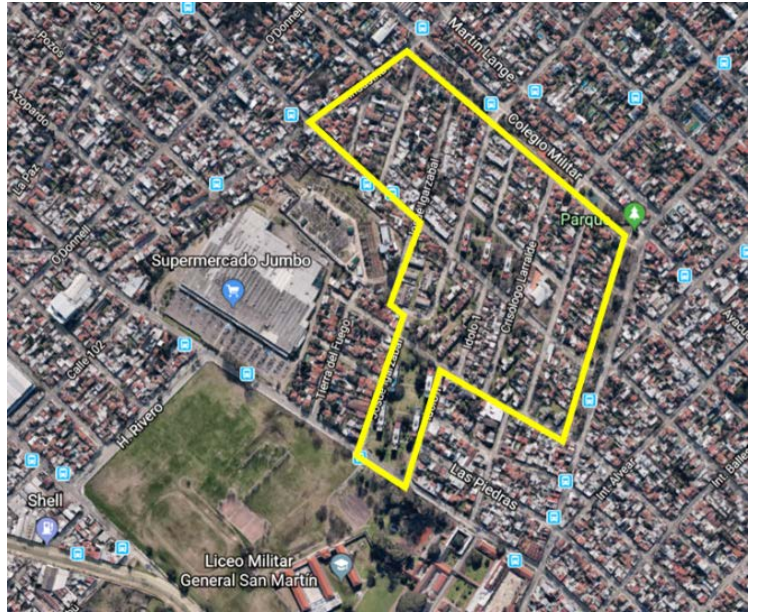

Fig.12: Identificación de un sector urbano con diversidad de tipologías de crecimiento donde predomina la tipología Polígono con conjuntos residenciales de diferente escala.

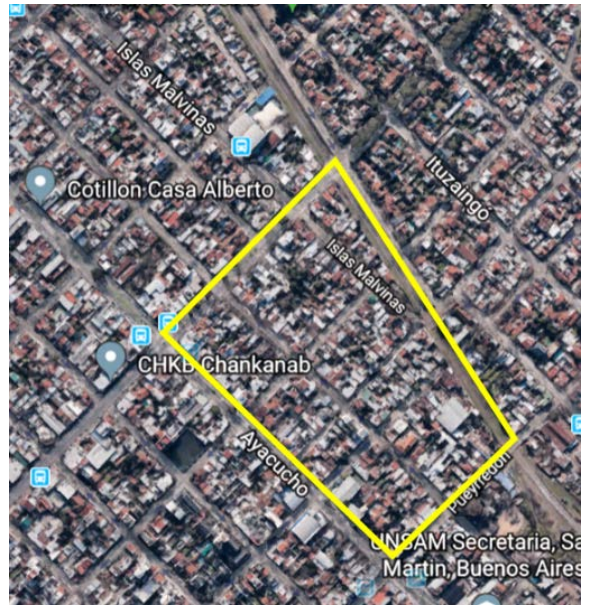

Fig.13: Identificación de sector urbano con tipología Ensanche, lindero al casco urbano del Partido. 


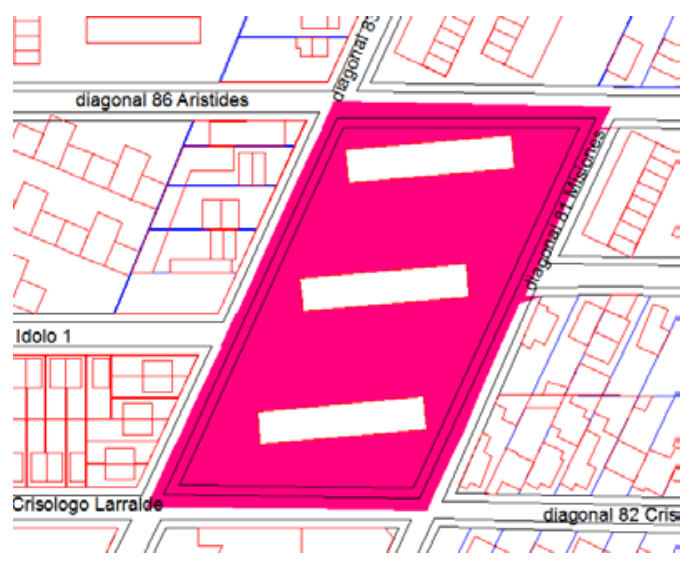

Fig. 14: Estudio de las condiciones de permeabilidad del tejido en tipología Ensanche en tipología Polígono
Fuente: Elaboración Propia en el marco del proyecto UBACyT 2014-2017.dirigido por la autora.

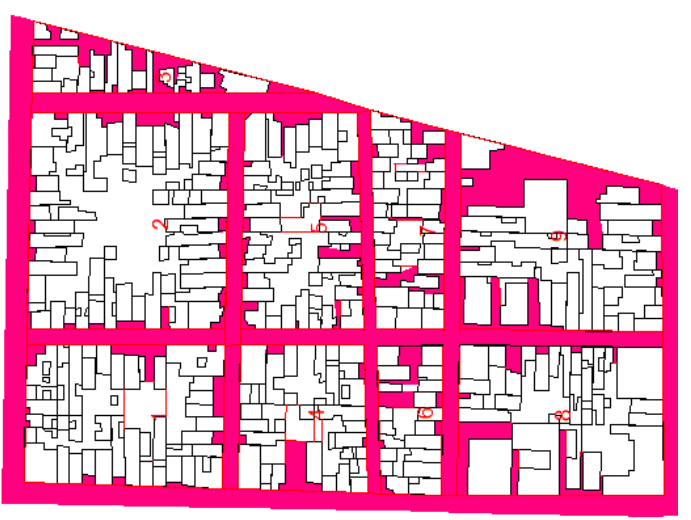

Fig. 15: Estudio de las condiciones de permeabilidad del tejido en tipología Ensanche

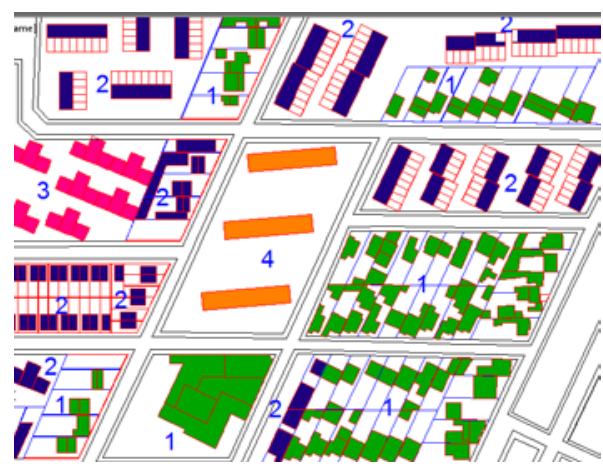

Fig 16: Estudio de la diversidad tipológica y de altura de edificación en el sector identificado en Fig 11.

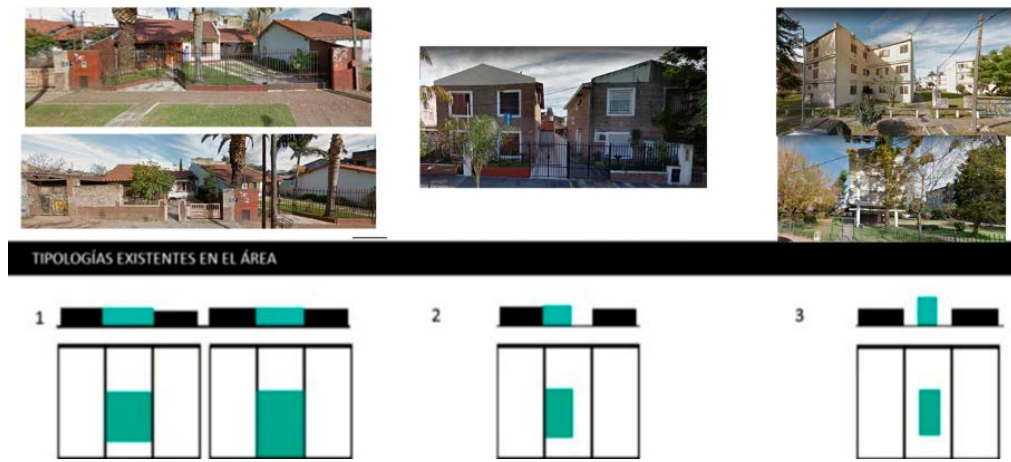

Fig.17: Estudio de la diversidad de tipologías edificatorias y uso del lote en el tejido residencial del sector identificados en Fig. 11

Fuente: Elaboración propia en base a imágenes elaboradas en el marco del proyecto UBACyT 2014- 2017 y de la asignatura GSCU.

Dentro de cada tipología seleccionada, se identifican como unidades de análisis a los espacios públicos más característicos, tomando como "típicos" a aquellos que constituyen la trama predominante del tejido dentro de cada mosaico urbano y como "atípicos" a aquellos que constituyen atipicidades y-o rupturas del mismo. (Fig. 18), identificando sus condiciones morfológicas y su potencialidad de acceso al sol dada por la proporción de cielo visible (Fig19).

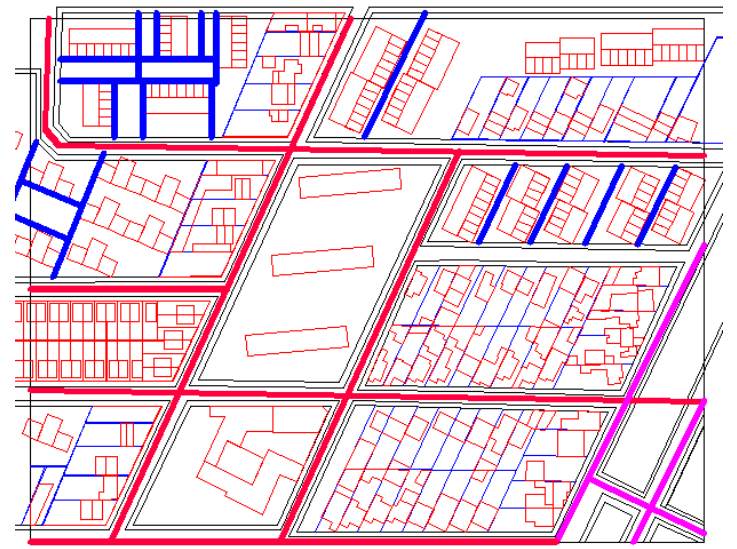

Fig.18: Identificación de diferentes tipos de espacios públicos (calles tipo y pasajes peatonales) en el sector identificado en Fig. 11

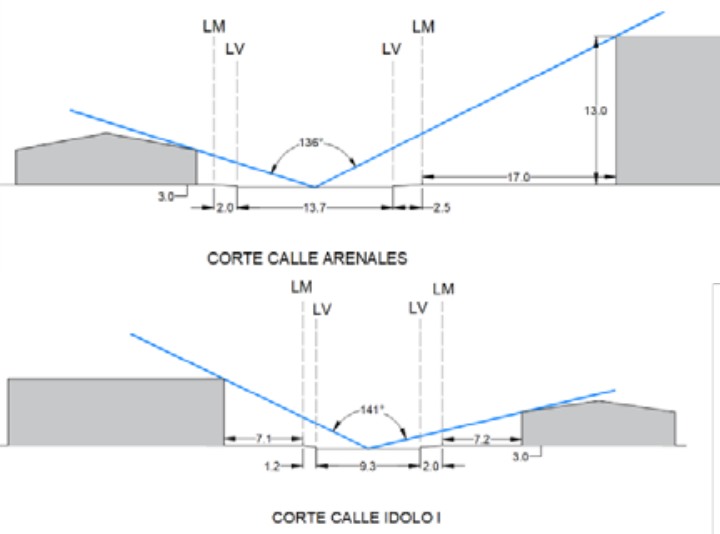

Fig. 19: Estudio de la proporción de cielo visible en diferentes calles del sector identificado en Fig. 11

Fuente: Elaboración propia en base a desarrollos hechos en el marco del proyecto UBACyT y de la asignatura GSCU - FADU- UBA

En esta etapa se establecerán las relaciones causa-efecto entre variables del hábitat construido y el entorno ambiental, desarrollando una matriz de interacción para evaluar condiciones de habitabilidad que estas interacciones propician en cada unidad. Se procede al fichado de las formas de crecimiento urbano con sus 
características morfológicas y materiales. Se elaboran planillas para la clasificación de las unidades de análisis e identificación de factores del hábitat construido que inciden en la habitabilidad urbana, teniendo en cuenta aspectos como: proporciones espaciales, materiales superficiales, condiciones de suelo, permeabilidad-continuidad de la envolvente, factor de cielo visible, tipo de coberturas, presencia, tipo y distribución de la vegetación.

\subsection{Desempeño ambiental de las unidades de análisis}

En esta etapa se prevé aplicar los Indicadores seleccionados a las Unidades de Análisis, observando y evaluando la forma en que dichas unidades, identificadas en cada mosaico o tipología de crecimiento urbano, se desempeñan a partir de la aplicación de los mismos. Los resultados obtenidos se confrontarán para establecer comparaciones entre unidades diferentes dentro de un mismo mosaico o unidades similares en diferentes mosaicos. El resultado de este procedimiento será insumo para la construcción del índice de Habitabilidad que se desarrolla en el capítulo subsiguiente. Asimismo, las mediciones de campo realizadas en diferentes épocas del año permitirán contrastar los datos provenientes de la estación de referencia con los registros tomados in situ y servirán para validar el uso de simuladores para la evaluación de condiciones de confort y satisfacción en las unidades de análisis seleccionadas. Los resultados de dichos estudios complementarán la información gráfica que dará cuenta del desempeño de las unidades de análisis y de las tipologías a las que estas pertenecen. Complementariamente, la aplicación de la matriz de interacción permitirá analizar y sacar conclusiones relacionando los resultados de las simulaciones con las particularidades de cada situación buscando relaciones causa - efecto entre los diferentes factores intervinientes en cada una.

\subsection{Indice de Habitabilidad del EPU}

Este capítulo tiene un objetivo propositivo en cuanto a la construcción de un Índice Sintético de Habitabilidad ISH para evaluar Espacios Públicos Urbanos, a partir de la selección de un set reducido de indicadores que integren dimensiones diversas sobre el EPU a fin de contribuir a la evaluación de la calidad ambiental y el confort de los mismos para el desarrollo de las actividades urbanas que los caracterizan, de acuerdo a las condiciones ambientales de la RMBA y micro-climáticas específicas del caso de estudio. A tal fin, se seleccionarán y adaptarán los indicadores más relevantes para determinar condiciones de habitabilidad urbana. Asimismo, dicho Índice será aplicado para la reconversión de un recorte urbano específico, detectado como deficitario en las condiciones de habitabilidad del EPU, a fin de demostrar la necesidad de considerar la variedad de aspectos que el mismo integra a partir de la incorporación de las variables seleccionadas y evaluar los beneficios obtenidos de su aplicación.

\subsection{Conclusiones}

El último capítulo de la tesis, constituirá la síntesis del conocimiento adquirido a lo largo del proceso de investigación desde el inicio hasta la redacción final de la misma: la metodología aplicada, los aprendizajes y las dificultades. También se reflexionará sobre los procesos y los resultados obtenidos en la Construcción del Indice de Habitabilidad y complementariamente sobre la potencialidad de transferencia de los conocimientos adquiridos a los ámbitos donde el proyectista toma decisiones que abordan la problemática urbana como una integralidad de variables que interactúan entre sí. Desde esa perspectiva, este capítulo estimula la reflexión sobre la necesidad de integrar a la normativa y a los procesos proyectuales, herramientas que permitan monitorizar la interacción entre variables de diseño y del soporte físico- ambiental, las cuales no pueden ser deslindadas entre sí, a los fines de garantizar condiciones urbanas favorables tendientes a: la mixtura de usos y usuarios, la vitalidad y seguridad urbana, la peatonalidad y sociabilidad de los espacios públicos, condiciones necesarias para la urbanidad.

\section{REFLEXIONES FINALES}

El Proyecto de Tesis, aprobado por la Comisión de Doctorado de la FADU UBA en septiembre de 2017, se encuentra en un estado de avance intermedio, con algunas presentaciones en congresos sobre los desarrollos parciales hechos en el marco de los seminarios doctorales y que formarán parte del contenido de la Tesis. Esta presentación expone a la comunidad científica la propuesta de tesis de la autora a fin de contribuir al debate sobre la necesidad de adaptación de indicadores de habitabilidad urbana al contexto ambiental específico de cada ciudad, evitando la adopción descontextualizada de los mismos, lo cual puede perjudicar la habitabilidad urbana de determinados sectores de la ciudad. El proyecto aquí presentado se encuentra en pleno desarrollo, por lo que esta presentación se focaliza en comunicar el estado de avance del mismo. 
La RMBA se caracteriza por un crecimiento no planificado, con centralidades que inicialmente se expandieron con el trazado de la red ferroviaria y se consolidaron luego con las autopistas metropolitanas, producto del modelo de desarrollo imperante, generando un tejido con grandes zonas mono-funcionales y densidades dispares sin correlato en la escala y cualificación de su espacio público. La selección de un área de estudio diversa y suficientemente representativa de las condiciones metropolitanas en cuanto a los aspectos urbanos, sociales, productivos y ambientales, como lo es el Partido de General San Martin, ha permitido detectar en su estructura urbana una variedad de tipologías morfológicas que sintetizan las formas de crecimiento de la RMBA. Asimismo, la variedad en el uso del suelo de dicho Partido, da como resultado una vasta diversidad en cuanto a tipologías de manzanas y lotes, producto de las diferentes formas de crecimiento en "parches", típicas de la región metropolitana, que acentúan los problemas de fragmentación urbana ya mencionados por autores como Kozak, citado anteriormente. En la escala local durante el último decenio, se produce un proceso creciente de densificación avalado por la normativa vigente que, por su desactualización, desconoce estándares de sustentabilidad urbana y favorece la proliferación de edificios en altura sin considerar la calidad ambiental del tejido urbano y espacio público resultantes. Paralelamente, a este proceso de densificación, en las últimas décadas se da un proceso de ocupación informal del suelo en forma extensiva sobre terrenos vulnerables del partido, perjudicando la calidad ambiental de estas zonas residenciales, que quedan escindidas de toda urbanidad y carentes de espacio público habitable, dadas sus condiciones de precariedad. Asimismo, el estudio de las condiciones ambientales originales del área de estudio, permitió verificar la ignorancia por parte de la planificación urbana local respecto de las características ambientales y físicas del territorio, con el relieve característico de la zona próxima al Rio Reconquista.

En este contexto, en el área de estudio el crecimiento residencial promovido por la normativa, se da en gran medida lote por lote, prevaleciendo la decisión del privado sobre aspectos de forma, materialidad, etc., lo cual conforma un tejido urbano predominantemente heterogéneo, donde el todo es el resultado de la suma de las partes, tal como lo expone Fernando Diez (1996). El estudio del espacio público y sus condiciones de habitabilidad como reflejo de la sustentabilidad del crecimiento suburbano, supone encarar el problema del crecimiento urbano desde un objetivo tendiente al bien común más allá de los intereses privados. Este enfoque, pretende priorizar la definición de un espacio público habitable a partir de la integración de aspectos de diseño y planificación del mismo, adecuándolo al contexto ambiental y favoreciendo su apropiación y uso, beneficiando al conjunto de la sociedad y promoviendo una cultura urbana más integrada.

La caracterización ambiental del área de estudio, con una marcada diferencia entre época estival e invernal y la consideración de las estrategias bioclimáticas recomendables para el clima específico, resulta fundamental para evaluar qué indicadores aplicados a otros contextos son transferibles al contexto local y cuales necesitan ser adaptados, o bien reemplazados por otros, que promuevan soluciones más ajustadas.

Para la identificación de las diferentes formas de crecimiento urbano representativas del RMBA, dentro del área de estudio, resultaron de gran aporte la metodologías de Sola Morales i Rubio, Higueras y Rodriguez Tarduchi quienes aportaron diferentes enfoques para identificar los mosaicos o tipologías de crecimiento urbano representativos de una ciudad, para luego identificar y clasificar los EPU de cada mosaico o forma de crecimiento, los cuales se constituyen en las unidades de análisis del trabajo. Estos aportes dan mayor sustento metodológico y permiten establecer relaciones causa-efecto entre las decisiones normativas, el hábitat urbano construido y los efectos en la habitabilidad y confort de los espacios públicos urbanos. Se destaca también el aporte del marco teórico consultado para la selección de indicadores de habitabilidad urbana que componen las dimensiones que integrarán el Indice a desarrollar.

Se prevé que resultados de esta investigación permitirán contribuir con estudios urbanos orientados a la densificación de las ciudades en la región metropolitana, así también como aportar ideas sustentables para reformas de códigos urbanísticos. En este contexto, se considera de especial interés y prioridad el avance en investigaciones orientadas a desarrollar indicadores de referencia para instrumentos normativos, que encaucen el crecimiento armónico de las ciudades en un marco de sustentabilidad urbana regional, con potencialidad de ser aplicado en instancias proyectuales de escala micro-urbana.

Se destaca que simultáneamente al desarrollo del proyecto de tesis definitivo, la autora co-dirigió un proyecto UBACyT 2014- 2017, en el marco del cual se hicieron algunas experiencias indagatorias sobre tipologías de crecimiento urbano, que también fueron transferidas a la enseñanza en el marco de la materia electiva Gestión Sustentable del Crecimiento Urbano durante los ciclos 2016 y 2017. Asimismo, el Proyecto de Tesis en curso, se encuentra registrado en la Secretaría de Investigaciones de la FADU- UBA como uno de los Proyectos PIT 
(Proyectos de Investigación de Tesistas), al cual pueden integrarse pasantes alumnos, por lo que se espera contribuir a la formación de RRHH en investigación en el marco de dicho proyecto.

\section{Reconocimientos}

Se agradece la colaboración de los organismos oficiales y a todas las personas que han contribuido con material documental y respondiendo a entrevistas personales para alimentar el acervo de información necesaria para el relevamiento e interpretación de los mismos. Asimismo, se destaca la orientación de la Arq. Silvia de Schiller como Directora de Tesis y la contribución de alumnos de la asignatura GSCU y pasantes del Proyecto UBACyT, que con sus prácticas aportaron material gráfico utilizado en esta presentación.

\section{BIBLIOGRAFÍA DE REFERENCIA}

Artículos en Serie Difusión 15: "Ambiente y Ciudad" (2001), Publicación de la SICyT- FADU- UBA, Editorial La Colmena ISSN 0328-2252 y ISBN 950-29-0637-3

- MURILLO, F. Y DE SCHILLER, S. "Calidad Ambiental y Costos de Desarrollo Urbano"

- DE SCHILLER, S. "Forma Edilicia y Tejido Urbano Sustentable"

- DE SCHILLER, S. Y EVANS, J. M. "El enfoque ambiental en el planeamiento urbano"

Artículos en "El Conocimiento del Ambiente. Aportaciones a la Arquitectura y el Urbanismo" (2010) Comp. Margarita González Gonzáles, Editado por Laredo Impresores, Mexicali, Nueva Méjico. ISBN 9787753-69-8

- DE SCHILLER, S. "Arquitectura para un Futuro Sustentable"

- CHAN LÓPEZ, D. "Arquitectura, Ambiente y los procesos de Investigación"

Artículos en "Compact Cities Sustainable Urban Form for Developing Countries" (2000) Editado por Mike Jenks y Rod Burgess, Gran Bretaña. ISBN 0-419-25130-8

- DE SCHILLER, S. Y EVANS, J.M., "Urban Climate and Compact Cities in Developing Countries"

- CARMONA, M. "The Regional Dimension of the Compact City Debate: Latin America"

Artículos en "Reflexiones... Los espacios Públicos" Publicación de la Secretaría de Extensión universitaria y

Bienestar Estudiantil FADU- UBA, Buenos Aires, (1995). ISBN N 950-29-0260-2

- SUÁREZ, O. "El Espacio Público"

- GORELIK, A. "La Ciudad de los Negocios"

- ARRESE, A. "El Espacio Público en Buenos Aires"

- MARENGO DE TAPIA M. "Los Espacios Abiertos Urbanos, su Significación como Integrante del Hábitat"

- $\quad$ EVANS, J. M. Y DE SCHILLER, S. "Espacios de Todos, Tierra de Nadie"

AEU-BCN Agencia de Ecología Urbana de Barcelona. "Certificación del Urbanismo Ecológico" Disponible en http://www.bcnecologia.net/sites/default/files/publicaciones/docs/certificacion-urbanismo-ecologico.pdf

AGENDA LOCAL 21 Red de Redes de Desarrollo Local Sostenible y Agencia de Ecología Urbana de Barcelona, "Sistema Municipal de Indicadores de Sostenibilidad", Barcelona, Noviembre de 2010, disponible en https://www.fomento.gob.es/NR/rdonlyres/82B973EA-5970-46F0-

BENTLEY ET AL, (1999) "Entornos Vitales. Hacia Un Diseño Arquitectónico Y Urbano Más Humano- Manual" Traducción de "Responsive Environments. A Manual For Designers" Editorial GG, Barcelona, ISBN 84$252-1731$

BORJA J. (1999). Ponencia en "Jornadas sobre Gestión del Territorio: El Desafío Metropolitano" Unidad de Gestión y Coordinación para el Área Metropolitana de Buenos Aires", Buenos Aires.

CHERMAYEFF S. Y ALEXANDER CH. (1963) "Comunidad y Privacidad", Edición original 1963, Traducido por Rubén Massera. Ediciones Nueva Visión. Col. Ensayos Buenos Aires, Argentina. 1984.

DE SCHILLER, S. (2004) "Sustainable Urban Form: Environment and Climate Responsive Design", Oxford, PhD, Julio 2004.

DE SCHILLER, S.; EVANS, J. M.; KULLOCK, D.; MURILLO, F., (2015), "Ordenamiento Territorial Y Ambiente", Jornadas de Investigación SI+TER, Secretaría de Investigaciones, Facultad de Arquitectura, Diseño y Urbanismo, Universidad de Buenos Aires, Buenos Aires. ISBN en trámite.

DE SCHILLER, S., EVANS, J.M. Y KATZSCHNER, L. (2001), "Isla De Calor, Microclima Urbano Y Variables De Diseño. Estudios En Buenos Aires Y Río Gallegos", en AVERMA, Avances en Energías Renovables y Medio Ambiente, Vol. 5, INENCO, Salta. ISSN 0329-5184.

DIEZ, F. "Buenos Aires y algunas constantes en las transformaciones urbanas." Editorial de Belgrano, Buenos Aires, Argentina, 1996. 
ECO, H. (2004). "Como Se Hace Una Tesis. Técnicas Y Procedimientos De Estudio, Investigación Y Escritura" Primera reimpresión en México, Editorial Gedisa Mexicana S.A. México D.F.

GEHL, J. (Reimpresión 2013) "La Humanización Del Espacio Urbano. La Vida Social Entre Los Edificios", Traducción de "Life Between Buildings", Serie Estudios Universitarios de Arquitectura, Editorial Reverté, Barcelona, España.

GORELIK, ADRIÁN (1998) "La Grilla y el Parque: espacio público y cultura urbana en Buenos Aires, 18871936" Buenos Aires: Univ. Nacional de Quilmes UNQ

HIGUERAS, E. (2007) "Urbanismo Bioclimático" Editorial Gustavo Gili, SL, Barcelona, España

IGLESIA, R. (2010) "Habitar, Diseñar". Ed. Nobuko, Buenos Aires, Argentina.

JIMENEZ, ROY ALLAN, (2016 a) "El Índice de Habitabilidad Urbana" Publicado el 18 de marzo de 2016 en https://lanuevarutadelempleocentroamerica.com/2016/03/18/el-indice-de-habitabilidad-urbana/ consultado el 20 de febrero de 2018

- (2016 b) "Habitabilidad y planificación de la escena urbana" Publicado el 6 julio, 2016 en https://urbe21blog.wordpress.com/2016/07/06/habitabilidad-y-planificacion-de-la-escenaurbana/ consultado el 20 de febrero de 2018

KOZAK, D. (2008) "Assesing Urban Fragmentation: The emergence of new typologies in central Buenos Aires" en "World Cities and Urban Form" Ed. Mike Jenks; Daniel Kozak y Pattaranan Takkanon, Publicado por Routledge simultáneamente en Oxon y USA y Canadá.

LEVA, G, "Indicadores De Calidad De Vida Urbana. Teoría Y Metodología" Publicación On Line de la Universidad Nacional de Quilmes, 2005. Disponible en http://hm.unq.edu.ar ISBN 45382-4288-2005

MINISTERIO DE DESARROLLO URBANO, GCABA, (2011). "Modelo Territorial 2010-2060" ISBN 978-98726328-5-4 disponible en: https://www.mininterior.gov.ar/planificacion/pdf/planes-loc/CABA/Modeloterritorial-2010-2060.pdf

MORENO OLMOS, S. H. "La habitabilidad urbana como condición de calidad de vida" Palapa, vol. III, núm. II, julio-diciembre, 2008, pp. 47-54, Universidad de Colima, México Disponible en: http://redalyc.uaemex.mx/src/inicio/ArtPdfRed.jsp?iCve=94814774007

MINISTERIO DE DESARROLLO URBANO, GCABA, "Indicadores de Sustentabilidad Urbana. Indice Sintético de Caminabilidad", disponible en: http://www.buenosaires.gob.ar/sites/gcaba/files/caminabilidad 0.pdf

ONU - HÁBITAT III (2016), Conferencia de las Naciones Unidas sobre la Vivienda y el Desarrollo Urbano Sostenible "Nueva Agenda Urbana", disponible en http://habitat3.org/wp-content/uploads/DraftOutcome-Document-of-Habitat-III-S.pdf

PINZON BOTERO y ECHEVERRY ALVAREZ. (2010) "Espacio Público, Cultura Y Calidad Ambiental Urbana Una Propuesta Metodológica Para Su Intervención" En Investigación y Desarrollo vol. 18, $\mathrm{n}^{\circ} 1$, Universidad Nacional de Colombia, Colombia - issn 0121-3261

RODRIGUEZ TARDUCHY, M. J. "Forma Y Ciudad. En Los Limites De La Arquitectura Y El Urbanismo" Cinter Divulgación Técnica SLL Primera Edición, Septiembre de 2011, España. ISBN978-84-939305-0-9

RUEDA PALENZUELA S. (1999) "Modelos e indicadores para ciudades más Sostenibles" Documento de la Fundación Forum Ambiental en http://www.forumambiental.org/pdf/huella.pdf

SOLÁ MORALES I RUBIÓ, M. (1997), "Las Formas De Crecimiento Urbano". Ediciones de la Universidad Politécnica de Catalunya. SL. Barcelona, Catalunya España

TUMINI, I. (2012). El Microclima Urbano en Espacios Abiertos. Estudios de Casos en Madrid. Tesis doctoral de la Universidad Politécnica de Madrid. Disponible en https://www.researchgate.net/publication/282854211 El microclima urbano en los espacios abiert os estudio de casos en Madrid

USGBC Green Building Challenge, "LEED for Neighborhood Development". Disponible en: www.usgbc.org ISBN: 978-1-932444-48-3 